\title{
THE DAILY EXCRETION OF RIBOFLAVIN, BIOTIN, PANTOTHENIC ACID, AND NICOTINIC ACID DERIVATIVES BY NORMALS
}

\author{
BY \\ JOSEPH FITZPATRICK AND SIDNEY LIONEL TOMPSETT \\ From the Biochemical Department, Royal Infirmary, Glasgow
}

(RECEIVED FOR PUBLICATION, NOVEMBER 8, 1949)

Cases of marked vitamin B deficiency are not infrequently admitted to hospital. Such usually show improvement when treated with preparations containing most of the members of the vitamin B complex. Clinical signs alone often make it difficult to assess whether a particular member or a number of the members of the vitamin B complex are involved. Clinical evidence would suggest that, in many cases, a number of the members of the vitamin B complex are involved. It is possible that laboratory investigations in conjunction with clinical evidence may help to throw some light on this problem. Members of the vitamin B complex exist in biological fluids in low concentrations, and for the majority there exist few or no suitable chemical methods for their determination. The recent development, however, of microbiological assay techniques has now opened up possibilities for laboratory investigations. Fitzpatrick and Tompsett (1949) have described microbiological techniques suitable for the determination of riboflavin and nicotinic acid concentrations in urine. In the present investigation the excretion of these substances and of biotin and pantothenic acid in the normal man is described. The investigation was made because in certain of them, e.g. nicotinic acid, there are wide variations in the normal ranges and most of the determinations have been carried out in the U.S.A. where dietary conditions are different.

Riboflavin appears to be excreted in urine in the free state and so far no other excretory product has been detected. Available figures, which appear to be mostly from American sources, suggest that in the normal man about $500-1,000 \mu \mathrm{g}$. are excreted per day (Bicknell and Prescott, 1946).

Both nicotinic acid and nicotinamide, which are microbiologically active towards $L$. arabinosus $17 ! 5$, are excreted in urine. Ranges for these, as quoted by Bicknell and Prescott (1946), vary extremely widely. Recently it has been shown that nicotinic acid is excreted mainly as two microbiologically inactive metabolites: $N_{1}$-methylnicotinamide (Huff and Perlzweig, 1945), and the 6 pyridone of $\mathrm{N}_{1}$-methylnicotinamide (Knox and Grossman, 1946 ; 1947). Using a fluorimetric method, Huff and Perlzweig (1947) have found that normal human urine contains 3-17 mg. per day of $\mathrm{N}_{1}$-methylnicotinamide. 
Biotin appears to be excreted in urine in the free state, and so far no other excretory product has been detected. Available figures, which are few and are of American origin, suggest that in the normal man about 14-111 $\mu \mathrm{g}$. are excreted per day (Bicknell and Prescott, 1946).

Pantothenic acid appears to be excreted in urine in the free state, and so far no other excretory product has been detected. Available figures, which also appear to be from American sources, show that in the normal man about 1.5$6.8 \mathrm{mg}$. are excreted daily (Bicknell and Prescott, 1946).

\section{Experimental Method}

Urine was collected from 37 persons on a normal diet. Specimens were collected for 24 hours in dark brown Winchester quart bottles containing $5 \mathrm{ml}$. of glacial acetic acid, and were thereafter preserved in a refrigerator.

The following assay methods were employed:

Riboflavin, microbiologically with $L$. casei (Fitzpatrick and Tompsett, 1949). 1949).

Nicotinic acid, microbiologically with L. arabinosus $17 / 5$ (Fitzpatrick and Tompsett,

$N_{1}$-methylnicotinamide, fluorimetrically by the method of Huff and Perlzweig (1947).

Biotin, microbiologically with $L$. arabinosus $17 / 5$ by a modification of the method of Barton-Wright (1945).

Pantothenic acid, microbio'ogically with $L$. arabinosus $17 / 5$ by a modification of the method of Barton-Wright (1945).

The results of the assays are shown in Table $\mathrm{I}$.

TABLE I

Daily Excretion of Riboflavin, Nicotinic ACID, N $_{1}$-Methylnicotinamide, Biotin, and PANTOTHENIC ACID BY 37 NoRmals

\begin{tabular}{|c|c|c|c|c|}
\hline Vitamin & Minimum & Maximum & Mean & $\begin{array}{l}\text { Standard } \\
\text { Deviation }\end{array}$ \\
\hline 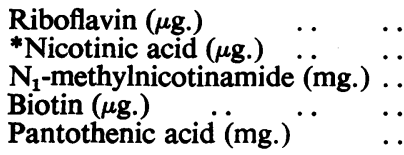 & $\begin{array}{l}65 \\
295 \\
2.0 \\
5 \\
2.5\end{array}$ & $\begin{array}{l}980 \\
2,000 \\
12.5 \\
20 \\
9.6\end{array}$ & $\begin{array}{c}345 \\
738 \\
5.8 \\
13 \\
5.7\end{array}$ & $\begin{array}{l}217 \\
313 \\
2.6 \\
4.2 \\
2.1\end{array}$ \\
\hline
\end{tabular}

* Includes all nicotinic acid derivatives (nicotinic acid, nicotinamide, nicotinuric acid) microbiologically active towards $L$. arabinosus $17 / 5$.

The figures for the excretion of riboflavin show a much wider range than those from the U.S.A., particularly at the lower levels. Figures for biotin excretion are found to be towards the lower end of the American range. Figures for pantothenic acid and $\mathrm{N}_{1}$-methylnicotinamide excretion are very similar to the American ranges.

\section{Summary}

Figures for the excretion of riboflavin, nicotinic acid, $\mathbf{N}_{1}$-methylnicot namide, biotin, and pantothenic acid by 37 normal persons are presented. 
REFERENCES

Barton-Wright, E. C. (1945). Analyst, 70, 283.

Bicknell, F., and Prescott, F. (1946). The Vitamins in Medicine. Heinemann. London. Fitzpatrick, J., and Tompsett, S. L. (1949). J. clin. Path., 2, 121.

Huff, J. W., and Perlzweig, W. A. (1945). J. biol. Chem., 150, 395, 483.

Knox, W. E., and Grossman, W. I. (1946). Ibid., 166, 391 ; 168, 363. 